\title{
Vulnerabilidade e risco de contaminação das águas do Sistema Aquífero Serra Geral na Bacia do Rio do Peixe/SC
}

\section{Vulnerability mapping and risk of water contamination of the Serra Geral Aquifer System in the Rio do Peixe Watershed, Santa Catarina State, Brazil}

\author{
Andréa Regina de Britto Costa Lopes ${ }^{1}$ e Luiz Fernando Scheibe ${ }^{2}$ \\ ${ }^{1}$ Dra. Programa de Pós-Graduação em Geografia. Centro de Filosofia e Ciências Humanas. \\ Universidade Federal de Santa Catarina - Florianópolis - SC. Brasil
}

${ }^{2}$ Prof. Dr. do Centro de Filosofia e Ciências Humanas. Universidade Federal de Santa Catarina - Florianópolis - SC. Brasil

Recebido: 30/07/14 - Revisado: 10/11/14 - Aceito: 10/05/15

\section{RESUMO}

O artigo apresenta uma versão modificada do método GOD (FOSTER et al., 2006), para a medição da vulnerabilidade de aquíferos. O método pondera o grau de confinamento da água subterrânea; a litologia geral dos estratos de cobertura; e a distância até o nível freático ou até o teto do aquífero confinado. A área de estudo é a bacia hidrográfica do Rio do Peixe, situada na região do Médio Oeste de SC, Brasil. Neste estudo, a densidade de lineamentos e a espessura e textura dos solos foram analisadas, em substituição aos descritores do método GOD. Para calcular o risco de contaminação do Sistema Aquífero Serra Geral (SASG), foram obtidas informações sobre o uso da terra. Cruzando o mapa de densidade de lineamentos com o mapa de vulnerabilidade dos solos, foi possivel delimitar áreas de maior ou menor vulnerabilidade intrínseca. O mapa do grau do risco de contaminação é o resultado da combinação do mapa de vulnerabilidade intrínseca com o mapa do risco potencial de contaminação. O mapa de vulnerabilidade intrínseca mostra que áreas com maior densidade de fraturas, falhas ou diques, coincidem com as áreas de solos menos espessos e de característica menos argilosa, resultando assim em áreas de alta ou muito alta vulnerabilidade. As áreas com maior potencial de risco de contaminação são ocupadas pelos corpos d'água, as urbanizadas e as cultivadas.

Palavras Chave: Sistema Aquifero Serra Geral. Método GOD. Vulnerabilidade. Contaminação ambiental. Bacia do Rio do Peixe

\begin{abstract}
The article presents a modified version of the GOD method (FOSTER et al., 2006) for measuring the aquifer vulnerability. The method considers the Groundwater occurrence (degree of confinement); the Overall lithology of cover layers; and the Distance to the water table or to the ceiling of the confined aquifer. The study area is the Rio do Peixe watershed, situated in the Middle West of the State of Santa Catarina, Southern Brazil. In this study, the lineaments density, the thickness and the texture of the soil were analyzed as descriptors of the GOD method. To calculate the risk of contamination of the Serra Geral Aquifer System (SGAS), informations on land use were also obtained. Crossing the maps of lineaments density and soil vulnerability, areas with high eror lower intrinsic vulnerability were delimited. The map of the contamination risk degree is the product of the combination of the intrinsic vulnerability map with the potential contamination risk map. The intrinsic vulnerability map shows that areas with higher density of fractures, faults or dykes, coincide with areas of thinner soils, with less clay, resulting in areas with higher potential contamination risk. Areas with higher potential contamination risk are those occupied by bodies of water, the urbanized and the cultivated areas.
\end{abstract}

Keywords: Serra Geral Aquifer System. GOD Method. Vulnerability. Environmental pollution. Rio do Peixe Watershed 


\section{INTRODUÇÃO}

Este artigo discute as relações entre recursos hídricos e uso da terra na Bacia do Rio do Peixe/SC, por meio do mapeamento da vulnerabilidade e do risco de contaminação dos recursos hídricos subterrâneos, considerando as limitações das ações públicas e sociais na preservação dos recursos hídricos.

O mapa de vulnerabilidade vai além do mapa de inventários e descreve as áreas que têm potencial para contaminação das águas subterrâneas. Essas áreas são determinadas pela correlação de alguns dos principais fatores, como propriedades geológicas e tipo de solo.

Por outro lado, o mapa de risco mostra as ameaças e a probabilidade de que ocorram riscos de contaminação das águas subterrâneas. O mapa de risco pode, ainda, mostrar as relações custo/benefício; potencial de perda e de outros efeitos socioeconômico potenciais de uma área.

De acordo com Highland e Bobrowsky (2008), mapas de risco usados em conjunto com mapas de uso da terra são valiosos instrumentos de planejamento, contribuindo com uma gestão quali-quantitativa.

Existem maneiras diferentes de avaliar a vulnerabilidade intrínseca e os riscos de uma determinada área, as quais podem ser resultado de coletas diretas a campo ou de forma indireta a partir do uso de ferramentas tecnológicas.

Samake et al. (2010) utilizam o mapeamento da vulnerabilidade para resgatar o potencial de contaminação em aquíferos de meio poroso em áreas de pressão agrícola no Norte da China. Pinheiro, Kosuth e Cernesson (2009) analisaram dados sobre contaminantes associados a pesticidas e seus efeitos na qualidade dos recursos superficiais na bacia do rio Itajaí, Santa Catarina. De Nardin e Robaina (2010) abordam zonas de fragilidade ambiental em uma bacia hidrográfica no Oeste do Rio Grande do Sul.

Peduzzi (2006) aponta que a importância do mapeamento da vulnerabilidade está em prover conhecimento sobre determinada área, uma vez que, de forma geral, a resposta da comunidade e dos governos a eventos adversos tem sido quase sempre com o propósito de mitigar os impactos. Ainda que haja intenção de investir na prevenção, a falta de informações sobre pontos mais vulneráveis, e o limitado tempo e recurso financeiro configuram-se como limitante dos planejadores.

Já com referência a conceituação, Shelton e Prouty (1979 apud HIGHLAND; BOBROWSKY, 2008) tomam os conceitos de suscetibilidade/vulnerabilidade como sinônimos e colocam que o mapa de suscetibilidade/vulnerabilidade vai além do mapa de inventários e deve descrever áreas que têm algum potencial para contaminação, por meio de correlação entre características geológicas e tipo de solo. Os autores apontam ainda que o mapa de risco pode revelar as possíveis ameaças e a probabilidade de que ocorra risco de contaminação da água subterrânea, considerando aspectos tais como o uso da terra de cada área. Este pode, ainda, mostraras relações custo/benefício potencial de perda ou de outros efeitos socioeconômico potenciais de uma área.

De acordo com o Ministério da Integração Nacional (BRASIL, 2000b), a vulnerabilidade pode ser entendida como a condição intrínseca ao corpo ou sistema receptor, podendo ser medida em termos de intensidade dos danos prováveis. Já o Risco é a "medida de danos ou prejuízos potenciais expressos em termos de probabilidade estatística de ocorrência e de intensidade ou grandeza das consequências previsíveis" ou a "relação existente entre a probabilidade de que uma ameaça de evento adverso ou acidente [...] se concretize, com o grau de vulnerabilidade do sistema receptor a seus efeitos".

De acordo com Foster et al. (2006), em hidrogeologia, o conceito de vulnerabilidade começou a ser usado intuitivamente a partir da década de 1970 na França, e de maneira mais ampla na década de 1980. Embora se referisse à suscetibilidade relativa dos aquíferos à contaminação antropogênica, o termo inicialmente era usado sem nenhum objetivo de definição formal. Já na atualidade o conceito de vulnerabilidade do aquífero à contaminação se refere ao conjunto de propriedades intrínsecas dos estratos que separam o aquífero saturado da superfície do solo. Essas propriedades determinam a suscetibilidade de um aquífero sofrer efeitos adversos de uma carga contaminante, aplicada na superfície.

Outro conceito que aparece associado à vulnerabilidade é o de perigo, o qual, conforme Foster et al. (2006), pode ser definido como a probabilidade de que a água subterrânea venha a apresentar concentrações de contaminantes superiores aos valores estabelecidos pela Organização Mundial de Saúde para a qualidade de água potável. Referenciam ainda que o conceito de perigo, por vezes, é substituído pelo termo risco.

Renfroe e Smith (2011) descrevem que uma combinação de classificação de impacto e de uma classificação de vulnerabilidade pode ser usada para avaliar o risco potencial. Essa matriz de risco pode representar riscos elevados por células vermelhas, riscos moderados pelas células amarelas, e os riscos baixos por células verdes.

Nesta perspectiva, é possível existir um aquífero com um alto índice de vulnerabilidade, mas sem risco de poluição caso não haja carga poluente, ou de haver um risco de poluição excepcional apesar de o índice de vulnerabilidade ser baixo. É, pois, importante precisar a diferença entre vulnerabilidade e risco de poluição. O risco é causado não pelas características intrínsecas do aquífero, mas pela existência de atividades poluentes, fator dinâmico, que pode ser controlado (NANNI et al., 2005).

\section{ÁREA DE ESTUDO}

A Bacia do Rio do Peixe (BRP) situa-se na região Meio Oeste do Estado de Santa Catarina, Brasil, (Figura 1) e se insere na Bacia Geológica do Paraná, uma ampla bacia intracratônica que teria se individualizado entre o final do período Siluriano e o início do Devoniano. Esta bacia foi preenchida por sedimentos sucessivos marinhos e continentais, depois recobertos, em evento concomitante com a ruptura do Gondwana e abertura do Atlântico Sul, de idade Juro-Cretácea, por um dos maiores conjuntos vulcânicos do planeta, resultando na denominada Formação Serra Geral (BIZZI et al., 2003; SCHEIBE, 1986).

A Formação Serra Geral é constituída por rochas vulcânicas, resultado de sucessivos derrames continentais, que 


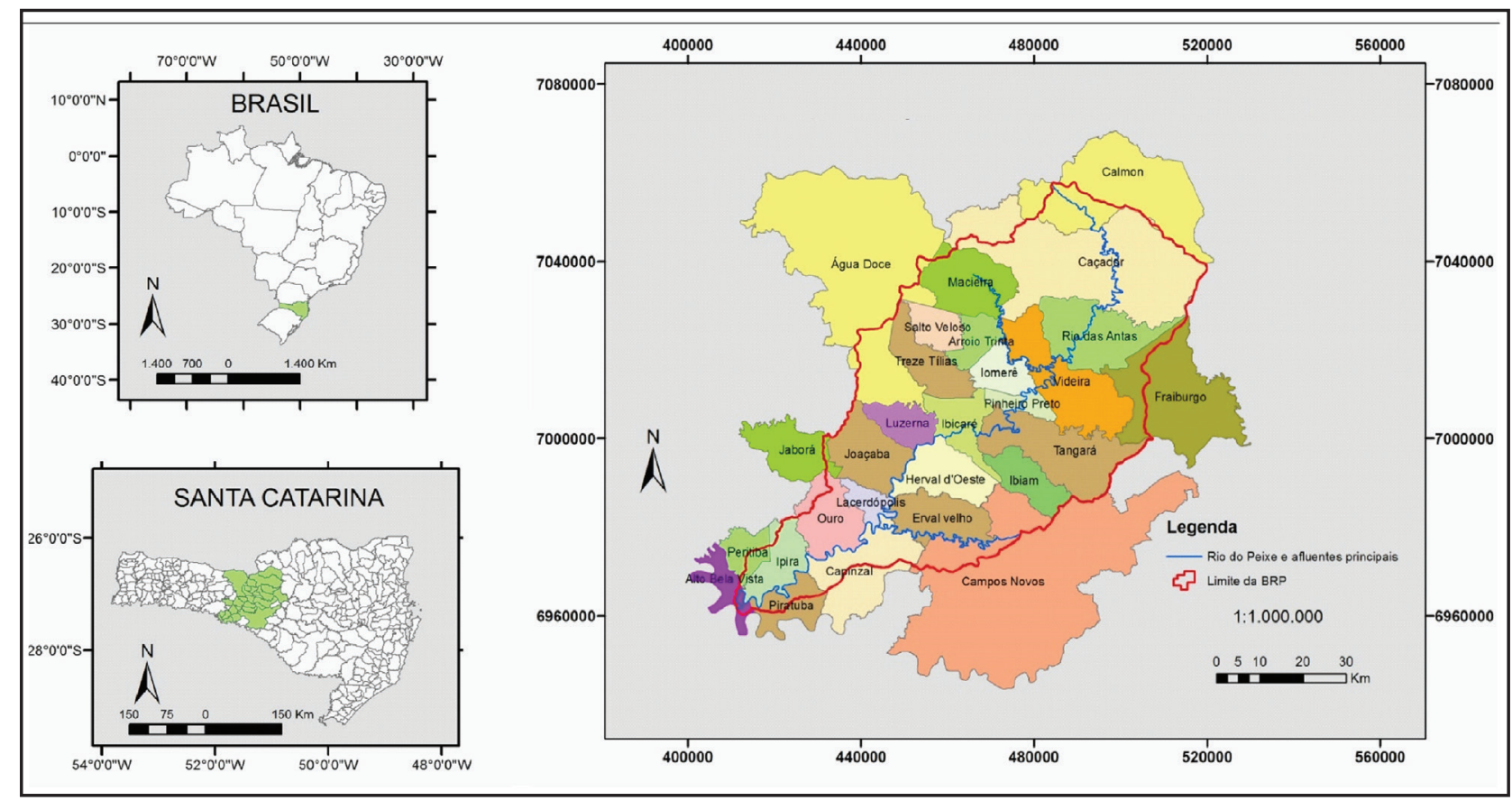

Figura 1 - Localização e municípios integrantes da Bacia do Rio do Peixe/SC

Fonte: Lopes (2012)

constituem, por sua vez, o Sistema Aquífero Serra Geral (SASG) (SCHEIBE; HIRATA, 2008), aquífero do tipo fraturado que é, atualmente, a principal fonte de águas subterrâneas em toda a região Oeste de Santa Catarina.

De acordo com Pellerin e Vilela (2011) o planalto ocidental de Santa Catarina exibe derrames com espessura média de 30 a 50 m, resultado das diferentes condições de deposição e resfriamento do magma. Apresenta encostas predominantemente convexas, de declividades médias bastante elevadas e níveis de patamares horizontalizados, resultado da erosão diferencial da sequência dos derrames basálticos.

A área de estudo registra ainda direções de fraqueza, principalmente nas direções N30-50W e N40-60E, cuja idade data do período pré-cambriano, reativadas durante e após os processos deposicionais.

O clima, do tipo temperado chuvoso, registra mínima e máxima anuais de 1000 e $2.200 \mathrm{~mm}$, e 1100 e $2.613 \mathrm{~mm}$, respectivamente, considerando dados dos municípios de Caçador e Videira (anos de 1947 a 2009) (SANTA CATARINA, 2010).

Considerando a interação entre os aspectos da geologia e do clima, a região apresenta um rico sistema de escoamento superficial, cujo principal curso de água é o Rio do Peixe, que dá nome à bacia. O Rio do Peixe nasce na Serra do Espigão (município de Calmon, Norte do Estado), e desemboca no Rio Uruguai, na divisa com o rio Grande do Sul, percorrendo 290 $\mathrm{km}$ e drenando uma área de $5.476 \mathrm{~km}^{2}$.

Destacamos que Freitas, Caye e Machado (2003) discutem a interconexão entre os Sistemas Aquífero Guarani - SAG - e o Sistema Aquífero Serra Geral - SASG. E que Scheibe (2006) visando acentuar a importância de uma gestão integrada das águas superficiais e subterrâneas, no Projeto Rede Guarani/ Serra Geral, propôs denominar de Sistema Aquífero Integrado Guarani/Serra Geral (SAIG/SG) ao conjunto do Sistema
Aquífero Guarani (SAG) com o Sistema Aquífero Serra Geral (SASG) (SCHEIBE; HIRATA, 2011).

As discussões sobre a conexão entre os Sistemas Aquíferos Guarani e Serra Geral também são apresentadas nas considerações de Zanatta e Coitinho (2002), que descrevem variações com relação à geometria desses aquíferos.

$\mathrm{Na}$ Bacia do Rio do Peixe, nos municípios de Erval Velho e Piratuba a cobertura de basalto se apresenta mais espessa, sendo o acesso às águas do SAG obtido a profundidades maiores, conforme perfil esquemático apresentado por Zanatta e Coitinho (2002) (Gráfico 1).

Gráfico 1 - Perfil: Espessura das Formações Guarani e Serra Geral em Santa Catarina (elipsoide vermelho assinala área da Bacia do Rio do Peixe)

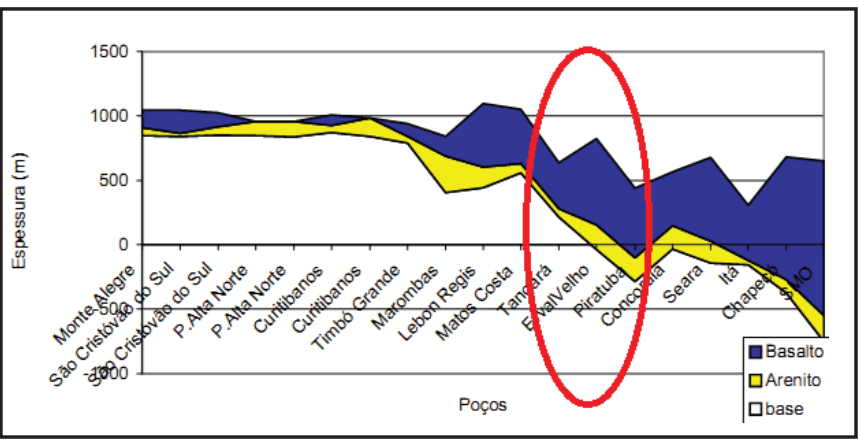

Fonte: Zanatta e Coitinho (2002)

Como produto da interação entre geologia e clima, a Bacia do Rio do Peixe apresenta solos dos grupos de associações: Cambissolos; Latossolos; solos Litólicos e Terra Bruna/Roxa Estruturada, segundo o Sistema Brasileiro de Classificação de 
Solo (SOLOS..., 2004). Foram amostrados pela EMBRAPA os municípios de: Videira, Fraiburgo, Campos Novos, Xaxim, Tangará, Erval Velho, Ibicaré, Jaborá, Rio das Antas, Piratuba, Campos Novos., Ipira, Joaçaba, Caçador, Treze Tílias, Água Doce, Joaçaba e Irani.

\section{MATERIAL E MÉTODOS}

Tomando como referência o método de caracterização da vulnerabilidade apresentado por Foster et al. (2006) e, denominado GOD, que pondera como descritores: Grau de confinamento da água subterrânea; Ocorrência de estratos de cobertura e Distância até o lençol freático ou o teto do aquífero confinado, nesta pesquisa, considerando a limitação de informações e as especificidades da área, essencialmente constituída por basaltos com graus diversos de faturamento, sem cobertura sedimentar apreciável, foi necessária uma adaptação do método GOD.

Foram consideradas nesta pesquisa a densidade de fraturas ou lineamentos e as características de textura e profundidade dos solos, que fornecem informações sobre teor de argila e sobre a espessura dos solos "que provocam a atenuação e/ou eliminação dos contaminantes no subsolo [...] justificandose uma modificação ao método (GODS) [...] como um quarto passo capaz de reduzir a pontuação geral em algumas áreas de alta vulnerabilidade".

Assim, considerando a limitação de informações para o mapeamento da vulnerabilidade intrínseca na Bacia do Rio do Peixe foram analisados os descritores:

Lineamentos, na modalidade densidade, obtidos a partir do Modelo Numérico do Terreno-MNT, de dados de radar Shuttle Radar Topography Mission-SRTM (MIRANDA, 2005), onde cada pixel de 90 × 90 metros apresenta um valor altimétrico).

A escala de trabalho para a caracterização dos lineamentos foi de 1:250.000, e o processo de delimitação considerou o comprimento de cada linha amostrada.

Os valores finais (mapa de densidade de lineamentos) foram convertidos em classes iniciais de vulnerabilidade, e disponibilizados em matriz semafórica, sendo tons em vermelho para vulnerabilidade alta e muito alta; tons de laranja a amarelo para vulnerabilidade moderada; e tons em verde para vulnerabilidade baixa a muito baixa, conforme tabela 1 .

Tabela1 - Classes de Vulnerabilidade considerando a densidade e a escala de peso do descritor Lineamento

\begin{tabular}{|c|c|c|c|}
\hline Descritor & Fator & $\begin{array}{l}\text { Escala } \\
\text { (Peso) }\end{array}$ & $\begin{array}{l}\text { Vulnerabilidade } \\
\text { (Classe) }\end{array}$ \\
\hline \multirow{4}{*}{ 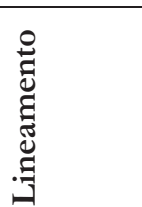 } & \multirow{4}{*}{ 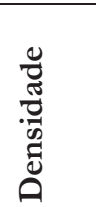 } & 006 a 0,2 & MuitoBaixa \\
\hline & & 0,3 a 0,7 & Baixa \\
\hline & & 0,8 a 1,0 & Moderada \\
\hline & & 1,1 a 2,0 & Alta \\
\hline
\end{tabular}

Solo, considerando os fatores profundidade e textura, a partir dos dados do Sistema Brasileiro de Classificação de Solo (SOLOS..., 2004).

As propriedades do solo foram subdivididas, quanto ao fator profundidade, nas subclasses disponíveis junto ao Sistema Brasileiro de Classificação de Solos (SOLOS..., 2004).

$\mathrm{Se}<60 \mathrm{~cm}$, valor de $1,0-$ muito alta vulnerabilidade, pois oferecem muito baixa atenuação da contaminação dos recursos hídricos subterrâneos;

De 60 a $150 \mathrm{~cm}$, valor 0,8 - vulnerabilidade alta;

$\mathrm{Se}>1,50 \mathrm{~cm}$, valor 0,5 - vulnerabilidade moderada, pois possuem uma camada maior de solo, na qual as reações bioquímicas se processam melhor, devido ao tempo necessário para transposição da camada de solo pela água.

E quanto o fator textura, nas subclasses:

Média - compreende composições granulométricas com menos que $35 \%$ de argila e mais de $15 \%$ de areia - valor 0,5 , vulnerabilidade moderada;

Argilosa - compreende classes texturais ou parte delas, tendo na composição granulométrica de 35 a 60\% de argila valor 0,3 , vulnerabilidade baixa;

Muito Argilosa - compreende a textura muito argilosa, classe com mais de $60 \%$ de argila, valor 0,1 , vulnerabilidade muito baixa, conforme tabela 2 . Registramos que as classificações de tipo de argila se limitam à classificação também empregada pelo Sistema Brasileiro de Classificação de Solo.

Tabela 2 - Escala de peso para cálculo da vulnerabilidade, considerando os fatores profundidade e textura e os respectivos atributos do descritor Solo

\begin{tabular}{|c|c|c|c|}
\hline Descritor & Fator & Atributo & Escala (Peso) \\
\hline \multirow{6}{*}{$\frac{0}{\circ}$} & \multirow{3}{*}{ 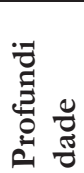 } & $<60 \mathrm{~cm}$ & 1,0 \\
\hline & & 60 a $150 \mathrm{~cm}$ & 0,8 \\
\hline & & $>150 \mathrm{~cm}$ & 0,5 \\
\hline & \multirow{3}{*}{ 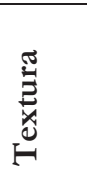 } & Média & 0,5 \\
\hline & & Argilosa & 0,3 \\
\hline & & $\begin{array}{l}\text { Muito } \\
\text { Argilosa }\end{array}$ & 0,1 \\
\hline
\end{tabular}

Os valores obtidos no mapa de classes de vulnerabilidade, a partir da correlação entre as informações obtidas com o descritor densidade de lineamentos e os do solo, considerando os fatores textura e profundidade, foram disponibilizados em matriz semafórica, onde tons em vermelho aparecem para vulnerabilidade alta e muito alta; tons de laranja a amarelo para vulnerabilidade moderada; e tons em verde para vulnerabilidade baixa a muito baixa.

Já para a determinação do risco de contaminação foi necessário o mapeamento do uso da terra e a atribuição de valores. Esta pesquisa seguiu as diretrizes recomendadas pelo Manual Técnico de Uso da Terra (BRASIL, 2013), e considerou:

- florestas, áreas com menor grau potencial de risco, em virtude do uso não receber insumos agrícolas e não permitir 


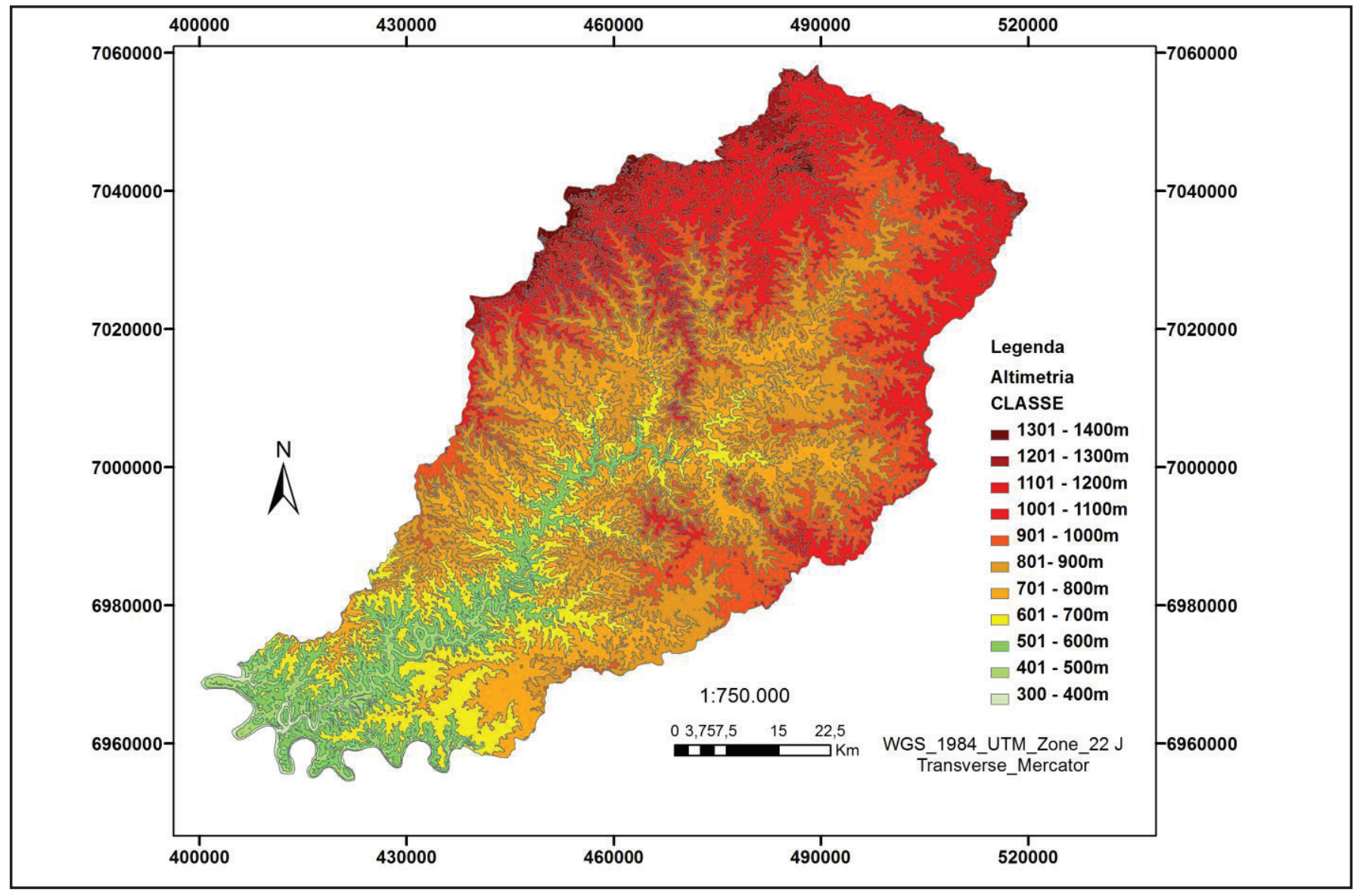

Figura 2 - Mapa de Altimetria da Bacia do Rio do Peixe, SC

Fonte: Lopes (2012)

ocupação humana. Peso 0,1;

- reflorestamentos, áreas com pequeno grau potencial de contaminação, considerando que o manejo requer poucos insumos. Peso 0,2;

- pastagem + solo exposto, áreas com grau potencial elevado, considerando a possibilidade de que podem receber diversos tipos de insumos, inclusive dejetos suínos. Peso 0,8.

- recursos hídricos superficiais, áreas com grau potencial intermediário conforme características sanitárias da região; registra-se grande possibilidade de receber efluentes não tratados. Peso 0,6 ;

- lavouras, áreas com grau potencial elevado, pois, conforme tipos de cultivo desenvolvido são passíveis de receber quantidade significativa de insumos. Somadas às áreas de produção pecuária, sujeitas a receber dejetos suínos, estes com grande potencial de poluição. Peso 0,8.

- áreas urbanizadas, áreas com maior grau potencial de risco em decorrência da retirada do solo, caracterizado como camada protetora dos recursos hídricos, somada à ausência de sistemas de tratamento de esgoto. Valor 1,0.

Ao se atribuir o valor a cada tipo de uso da terra, esta pesquisa apoiou-se também nas informações divulgadas pela Pesquisa Nacional de Saneamento Básico, que revelou que do universo de 202 municípios amostrados, de um total de 293, 79 municípios registraram algum tipo de contaminação na captação superficial de água. Das contaminações mais significativas foram citadas: contaminação por resíduos de agrotóxicos e por esgotamento sanitário (BRASIL, 2000a).

Foi elaborado um mapa de altimetria (Figura 2), evidenciando as variações de altitudes na faixa entre 300 e $1400 \mathrm{~m}$, no entanto este fator não foi considerado no presente estudo. Considerações sobre condutividade hidráulica, também não foram incluídas. E devido à escala de trabalho, não foram considerados diretamente os efluentes de criação de animais

Os descritores foram sistematizados em matriz numérica e inseridos em SIG. Para tratamento dos dados foram utilizadas técnicas de geoprocessamento por meio dos softwares IDRISI 32 e ArqGis 9.3.

\section{LIMITAÇÕES DOS MÉTODOS DE AVALIA- ÇÃO DA VULNERABILIDADE}

Ao se ponderar sobre técnicas de caracterização da vulnerabilidade dos recursos hídricos subterrâneos, deve-se considerar que, em maior ou menor grau, toda água subterrânea é vulnerável à contaminação (FOSTER et al. (2006).

Do ponto de vista científico, os resultados seriam mais consistentes quando se realizasse uma avaliação de vulnerabilidade para cada tipo de contaminante, ou, sendo isso inviável, para cada classe de contaminante ou para cada grupo de atividades separadamente. Entretanto, mapas de vulnerabilidade para cada 
tipo específico de contaminante ou grupo de contaminantes geram uma infinidade de representações para cada área, o que dificultaria a análise, exceto para uma avaliação e controle da contaminação difusa. Dessa forma, entende-se que seja mais prudente aplicar um índice de vulnerabilidade único e integrado, de caráter mais geral, do que uma série de índices parciais (FOSTER et al., 2006).

Foster et al. (2006) aponta ainda que aspectos tais como a quantidade e qualidade dos dados, e os recursos humanos e financeiros, devem ser considerados na avaliação da vulnerabilidade de um aquífero.

\section{RESULTADOS E DISCUSSÃO}

A partir do cruzamento do mapa de Densidade de lineamentos (Figura 3) com o mapa de Vulnerabilidade dos solos (Figura 4), foi possível delimitar áreas com maior ou menor vulnerabilidade intrínseca, conforme informações apresentadas no mapa de Vulnerabilidade Intrínseca (Figura 5).
O mapa de vulnerabilidade intrínseca mostrou áreas com maior densidade de fraturas, falhas ou diques, coincidindo com as áreas de solos menos profundos, de característica menos argilosa.

Essas áreas podem se constituir em faixas de maior vulnerabilidade do Sistema Aquífero Serra Geral (podendo supostamente, em alguns casos, chegar até o nível do Sistema Aquífero Guarani, pela continuidade vertical das fraturas registradas na área de estudo).

Registramos novamente que esta análise considerou no mapa de vulnerabilidade intrínseca a densidade de lineamentos no lugar de Grau de confinamento e Distância até o lençol freático.

Já o Mapa de risco de contaminação das águas subterrâneas na Bacia do Rio do Peixe/SC (Figura 7) é produto da combinação do mapeamento da vulnerabilidade intrínseca (Figura 5) e do mapa de potencial de risco de contaminação dos recursos hídricos, considerando os principais tipos de cobertura do uso da terra (Figura 6).

No mapa de potencial de risco de contaminação pelos tipos de cobertura do uso da terra os valores variaram de: 1,1 a

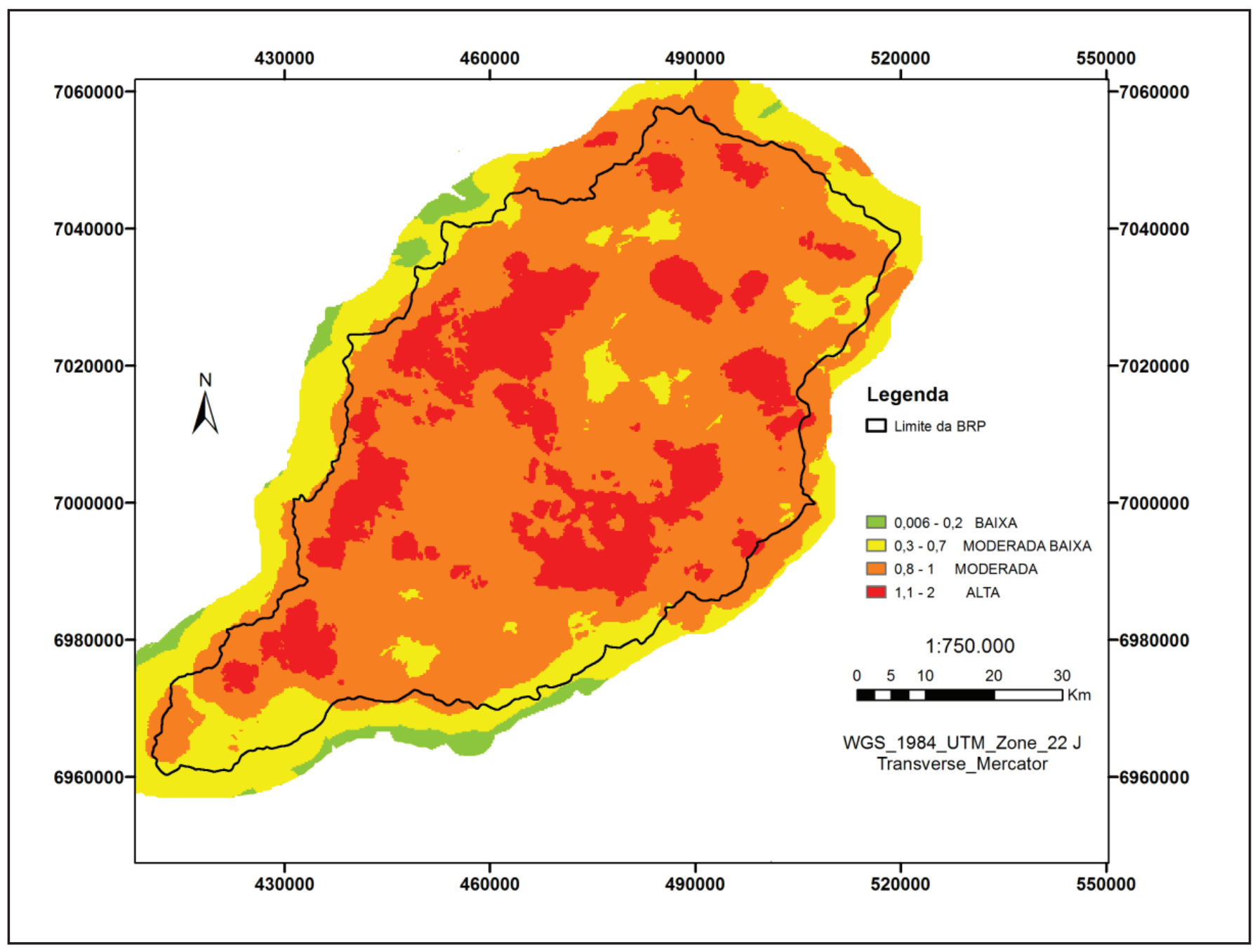

Figura 3 - Mapa de classes de vulnerabilidade para o fator Densidade de lineamentos na Bacia do Rio do Peixe/SC Fonte: Lopes (2012) 


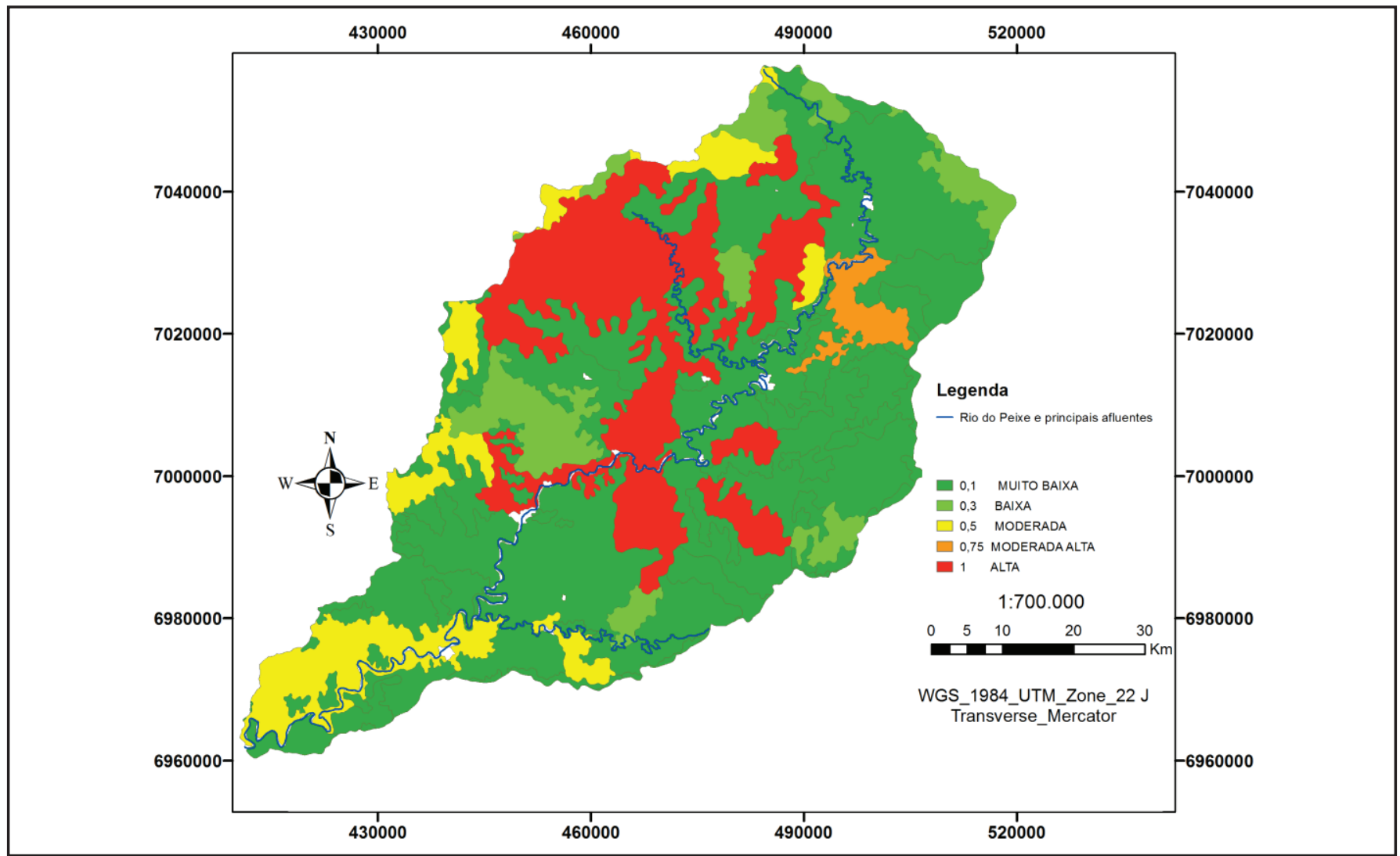

Figura 4 - Mapa de classes de vulnerabilidade do solo, considerando textura e profundidade na Bacia do Rio do Peixe/SC Fonte: Lopes (2012).

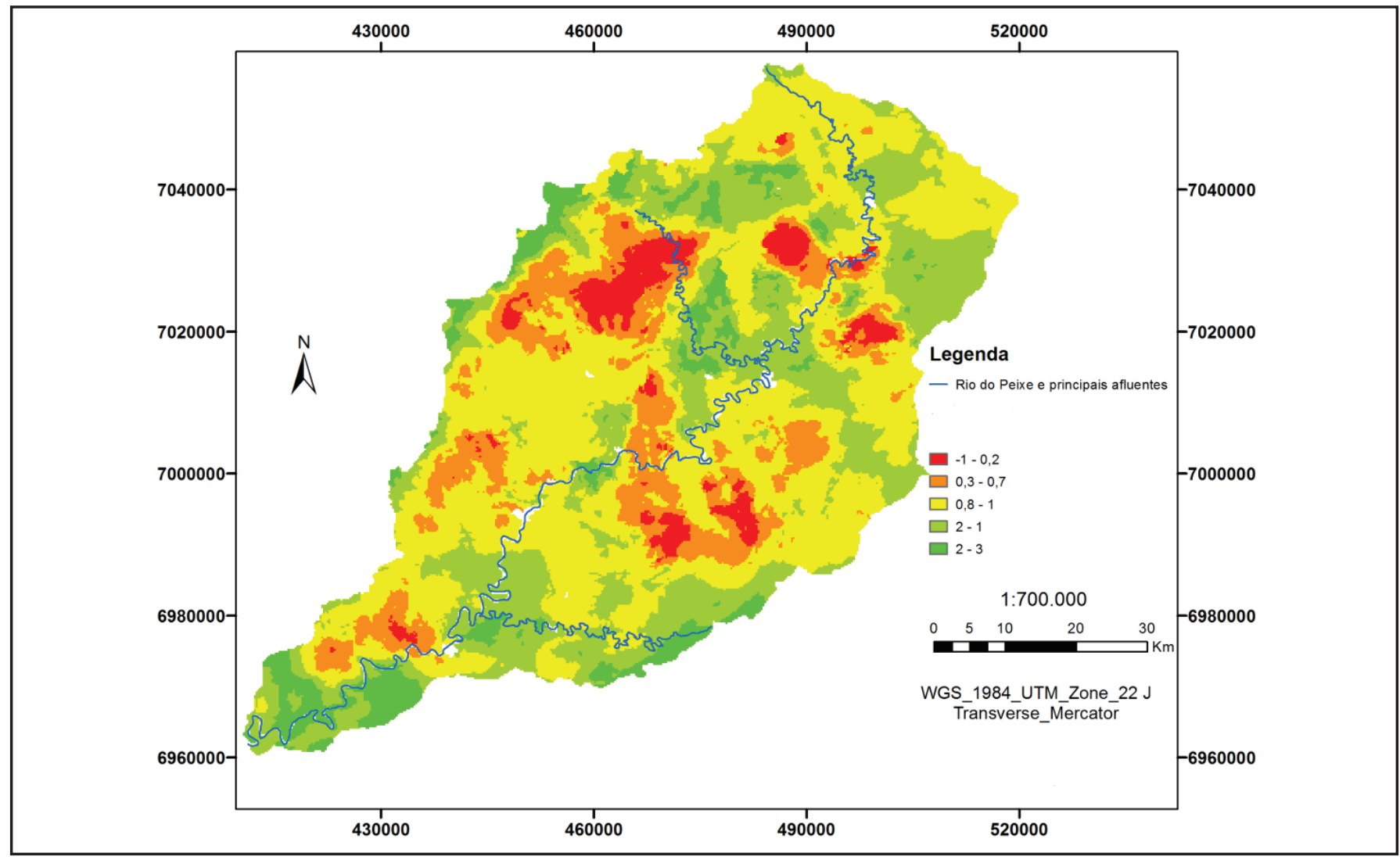

Figura 5 - Mapa de vulnerabilidade intrínseca à contaminação das águas subterrâneas na Bacia do Rio do Peixe/SC Fonte: Lopes (2012) 


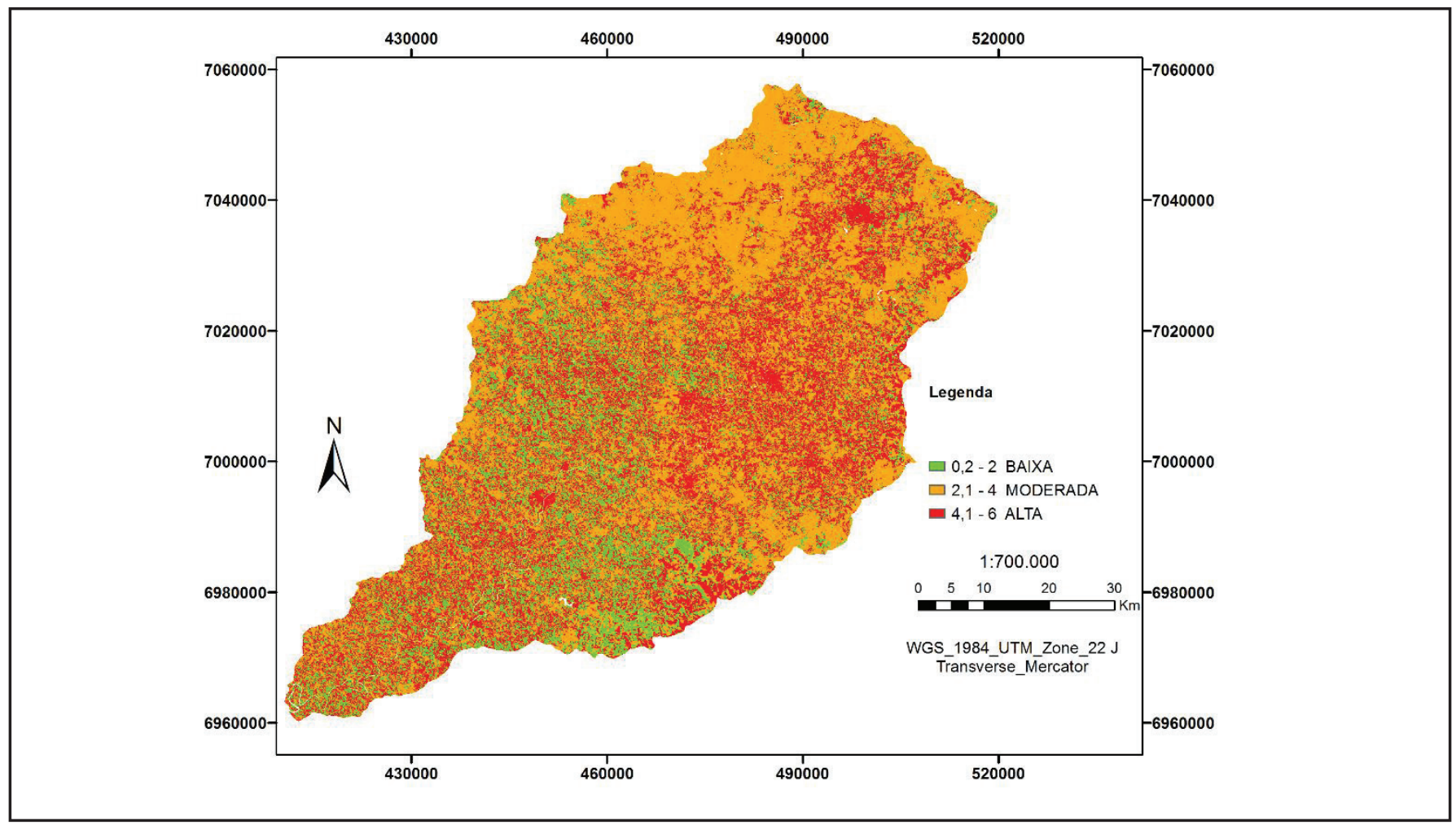

Figura 6 - Mapa de potencial de risco de contaminação dos tipos de cobertura e uso da terra na Baciado Rio do Peixe/SC Fonte: Lopes (2012)

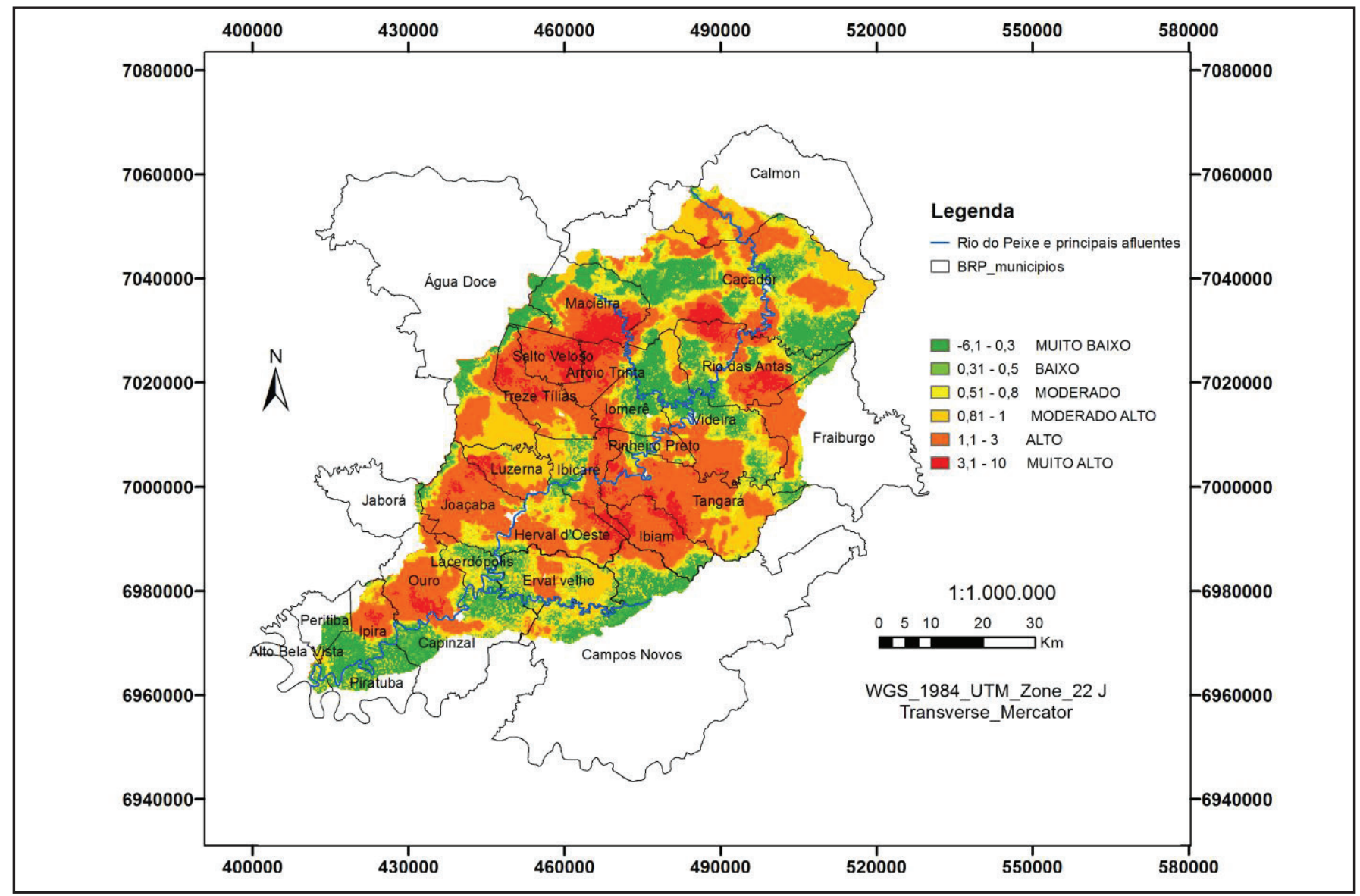

Figura 7 - Mapa de risco de contaminação das águas subterrâneas na Bacia do Rio do Peixe/SC Fonte: LopeS (2012) 
3,0 - Baixo; 3,1 a 4,0 - Moderado; 4,1 a 6,0 - Alto. Este mapa considerou os principais tipos de cobertura do uso da terra que pudessem ser mapeados na escala do estudo a partir de imagens de satélites, para fornecer indicadores de maior risco de contaminação dos recursos hídricos.

O mapa de cobertura dos tipos de uso da terra representou os principais tipos de uso dos anos de 2008/2009. Foram registrados: 216.285 hectares de florestas (39,3\%); 167.881 hectares de solo exposto (30,5\%); 58.887 hectares de cultivos em diversos estágios de desenvolvimento (10,7\%); 50.558 hectares de pastagens $(9,2 \%) ; 46.904$ hectares de reflorestamentos (8,5\%); e 1.488 hectares de rios, açudes ou outro recurso hídrico superficial $(0,3 \%)$. As áreas de solo exposto, bem como parte das áreas de pastagens, podem representar áreas de preparo para cultivos ou áreas de corte de reflorestamento (Tabela 3).

Tabela 3 - Uso da terra na Bacia do Rio do Peixe/SC

- 2008 - Hectares e Porcentagem

\begin{tabular}{l|c|c}
\hline Classe & Hectares & \% \\
\hline Urbanização & 4983 & 0.9 \\
\hline Reflorestamento & 46904 & 8.5 \\
\hline Floresta & 216285 & 39.3 \\
\hline Solo exposto & 167881 & 30.5 \\
\hline Cultivos & 58887 & 10.7 \\
\hline $\begin{array}{l}\text { Recursos hídricos } \\
\text { superficiais }\end{array}$ & 1488 & 0.3 \\
\hline Pastagem & 50558 & 9.2 \\
\hline Nuvens & 2857 & 0.5 \\
\hline Total & 549843 & 100 \\
\hline
\end{tabular}

\section{Fonte: Lopes, 2012}

Todas as informações do mapa de uso da terra foram validadas por observações com registros de coordenadas geográficas coletadas por meio de trabalhos de campo.

No mapa de Risco de contaminação das águas subterrâneas na Bacia do Rio do Peixe/SCas áreas delimitadas como de potencial de risco Alto são aquelas ocupadas pelos corpos hídricos, pela urbanização e pelas lavouras. As áreas dos corpos hídricos (rios, lagoas, reservatórios) em conjunto com as áreas urbanizadas foram consideradas de alto potencial de risco em virtude dos municípios da bacia, tanto na área urbana quanto rural, não possuírem sistemas de tratamento de efluentes: nesses espaços os efluentes resultantes de atividades industriais (especialmente, agroindústrias) ou urbanas acabam por atingir os recursos hídricos superficiais com pouca ou nenhuma desinfecção. As áreas de cultivos (assim como as de solos expostos) foram igualmente consideradas de alto potencial em razão de a literatura referenciar casos de intoxicação e a significativa presença de insumos químicos na produção agrícola (CARVALHO; NODARI; NODARI, 2009).
As áreas classificadas como de potencial Moderado, incluíram áreas de pastagens (com algum tipo de insumo). E as áreas delimitadas como de potencial de risco Baixo foram aquelas ocupadas por florestas, onde não ocorrem lançamentos de efluentes (sejam agrícola ou industrial), e as áreas destinadas ao reflorestamento com pequeno manejo de insumos.

A partir dessas considerações, o mapa de risco de contaminação das águas subterrâneas na Bacia do Rio do Peixe/SC (Figura 7) é apresentado nas categorias de valores: - 6,1 a - 0,3 como Muito Baixo Risco; - 0,31 a 0,5, como Baixo Risco; 0,51 a 0,8 como Risco Moderado; 0,81 a 1 como Risco Moderado Alto; 1,1 a 3 como Risco Alto e 3,1 a 10 como Muito Alto Risco. Da mesma forma que o mapa de vulnerabilidade intrínseca, apresenta suas classes em matriz semafórica.

As análises referentes à vulnerabilidade intrínseca e do risco de contaminação das águas subterrâneas a partir desta adaptação do método GODS, revelaram que o descritor lineamentos teve um importante peso quanto à classificação dos graus - Alto, Moderado e Baixo - uma vez que as áreas registradas como de maior densidade de lineamentos se repetiram também como de maior vulnerabilidade intrínseca.

\section{CONCLUSÕES}

O mapeamento da vulnerabilidade e do risco, dentro das limitações da escala, mostrou-se hábil para espacializar áreas de maior ou menor vulnerabilidade e risco na área de estudo.

Da mesma forma, pode, ainda, oferecer orientações quanto à ocupação e uso da terra, considerando aspectos de proteção das águas subterrâneas do SASG.

A metodologia utilizada apresentou-se adequada ao desenvolvimento do trabalho. O uso de geotecnologias se mostrou eficiente como ferramenta de análise na espacialização e distribuição dos recursos naturais, no uso da terra e no diagnóstico preliminar dos mapeamentos dos tipos de uso da terra, mapeamento da vulnerabilidade e do risco.

Da mesma forma, o uso de um sistema de informação geográfica, a partir de dados sobre características físicas e distribuição dos tipos de solos, usos da terra, foi capaz de sintetizar e relacionar informações sobre a bacia. Outros mapas podem ser gerados, a partir de novos cruzamentos, podendo, assim, produzir outras informações que também orientem no processo de tomada de decisão e ou conhecimento das limitações e possibilidades de uma gestão integrada, de forma a subsidiar meios mais sustentáveis de exploração da terra.

\section{AGRADECIMENTOS}

Ao Projeto Rede Guarani/Serra Geral (www.rgsg.org. br) e ao CNPq N $556644 / 2009-3$, pela concessão da bolsa de pesquisa através do Edital MCT/CNPq/CT-Hidro no 22/2009, e bolsa de Pesquisador II. 


\section{REFERÊNCIAS}

BIZZI, L. A.; SCHOBBENHAUS, C.; VIDOTTI, R. M.; GONÇALVES (Ed.). Geologia, tectônica e Recursos Minerais do Brasil. Brasília: CPRM, Serviço Geológico do Brasil, 2003. Disponível em: <www.cprm.gov.br/publique;media.capII.pdf>. Acesso em: 18 jan. 2010.

BRASIL. Instituto Brasileiro de Geografia e Estatística. Diretoria de Geociência. Coordenação de Recursos naturais e Estudos Ambientais. Manual técnico de uso da terra. 3. ed. Rio de Janeiro: IBGE, 2013. Disponível em: < http://loja.ibge.gov.br/manualtecnico-de-uso-da-terra.html>. Acesso em: 18 out. 2013.

BRASIL. Instituto Brasileiro de Geografia e Estatística. Diretoria de Pesquisas, Departamento de População e Indicadores Sociais. Pesquisa Nacional de Saneamento Básico. Rio de Janeiro: IBGE, 2000a. Disponível em: <http://www.ibge.gov.br/home/estatistica/ populacao/condicaodevida/pnsb/esgotamento_sanitario/ esg_sanitario50.shtm>Acesso em: 18 jan. 2010.

BRASIL. Ministério da Integração Nacional. Secretaria de Defesa Civil. Politica Nacional de Defesa Civil. Brasília: [s.n.], 2000b. Disponível em: <http://www.disaster-info.net/PEDSudamerica/leyes/leyes/suramerica/brasil/sistemnac/Politica_ Nacional_Defensa_Civil.pdf>. Acesso em: 18 mar. 2010.

CARVALHO, M. M. X. de; NODARI, E. S.; NODARI, R. O. Avanço no Uso de Agrotóxicos e das Intoxicações Humanas em Santa Catarina. Rev. Bras. Agroecologia, v. 4, n. 2, p. 2762-2766, nov. 2009. Disponível em: < http://www.aba-agroecologia.org. $\mathrm{br} / \mathrm{revistas} /$ index.php/rbagroecologia/article/view/8781>. Acesso em: 20 out. 2010.

DE NARDIN, D.; ROBAINA, L. E. S. Zoneamento Geoambiental no Oeste do Rio Grande do Sul: um estudo em Bacias Hidrográficas em processo de arenização. Soc. Naturęa, v. 22, n. 3, p. 487-502, dez. 2010. Disponível em: <http://www. scielo.br/pdf/sn/v22n3/06.pdf>. Acesso em: 18 dez. 2011.

FOSTER, S.; HIRATA, R.; GOMES, D; D’ELIA, M; PARIS, M. Proteção da qualidade da água subterrânea: um guia para empresas de abastecimento de água, órgãos municipais e agências ambientais. São Paulo: Servmar - Serviços Técnicos Ambientais, 2006. Banco Mundial. Edição brasileira.

FREITAS, M. A.; CAYE, B. R.; MACHADO, J. L. F. (Org.) PROESC: diagnóstico dos recursos hídricos subterrâneos do oeste do Estado de Santa Catarina - Projeto Oeste de Santa Catarina. Porto Alegre: CPRM/SDM-SC/SDA-SC/EPAGRI, 2003.

HIGHLAND, L. M.; BOBROWSKY, P. O manual de deslizamento - um guia para a compreensão de deslizamentos. Contribuição e tradução: Paulo R. Rogério e Juarês José Aumond. Reston, Virginia: U.S.: Geological Survey, 2008. Disponível em: <www. gfdrr.org/sites/gfdrr/files/publication/Deslizamentos_M5DS. pdf>. Acesso em: 18 jan. 2010.

LOPES, A. R. B. C. Recursos hídricos e uso da terra na bacia do Rio do Peixe/SC, mapeamento das áreas de vulnerabilidade e risco de contaminação do sistema aquifero Serra Geral. 2012. Tese (Doutorado) - Centro de Filosofia e Ciências Humanas, Universidade Federal de Santa Catarina, Porto Alegre, 2012.

MIRANDA, E. E. de; (Coord.). Brasil em Relevo. Campinas: Embrapa Monitoramento por Satélite, 2005. Disponível em: $<$ http://www.relevobr.cnpm.embrapa.br>. Acesso em: 18 jan 2010 .

NANNI, A. S.; FREITAS, M. A.; TEDESCO, M. A.; BINOTTO, R. B. Vulnerabilidade natural e risco de contaminação do aquífero Serra Geral pela suinocultura na região das missões - RS. In: SIMPÓSIO BRASILEIRO DE RECURSOS HÍDRICOS, 16., 2005, João Pessoa. Anais... [S.l.: s.n.], 2005. Disponível em: <www.dpi.inpe.br/spring/portugues/arquivos_publicacoes / xvi_sbrh.pdf $>$. Acesso em: 12 maio 2012.

PEDUZZI, F. The disaster risk index: overview of a quantitative approach. In: BIRKMANN, J. (Ed.). Measuring vulnerability to natural hazards. New York: United Nations University Press, 2006. p. 171-181. Disponível em:<www.ipcc.ch/pdf/special./ SREX-Chap2_FINAL.pdf>. Acesso em: 10 jan. 2010.

PELLERIN, J. R. G. M.; VILELA, J. H. Relatório de vistoria geológicageomorfológica: município de Coronel Freitas/SC. Florianópolis: Universidade Federal de Santa Catarina - UFSC. Centro Universitário de Estudos e Pesquisas sobre Desastres - CEPED UFSC, 2011. Coordenador do Projeto: Prof. Antônio Edésio Jungles.

PINHEIRO, A.; KOSUTH, P., CERNESSON, F. Desenvolvimento de um Indicador de Risco de Contaminação das Águas Superficiais por Pesticidas: Aplicação a Bacia do Itajaí - Brasil. RBRH: revista brasileira de recursos hídricos, v. 14, n. 1, p. 5-14, jan./ mar. 2009. Disponível em: <https://www.abrh.org.br/sgcv3/ UserFiles/Sumarios/52c6de5a6712e9c68278856c2e1b7d34_ bb0a6de9365d6cdb64fb5905087d7d2c.pdf>. Acesso em: 20 jan. 20110.

RENFROE, N. A.; SMITH, J. L. Threat/Vulnerability Assessments and Risk Analysis. Washington, DC: National Institute of Buiding Sciences, 2011. Disponível em: <http://www.wbdg. org/resources/riskanalysis.php>. Acesso em: 19 out. 2011.

SAMAKE, M.; TANG; Z. H.; HLAING, W.; M’BUE, I.; Kasereka, $\mathrm{K}$. Assessment of groundwater pollution potential of the datong basin, Northern China. J. Sustainable Develop., v. 3, n. 2, June 2010. Disponível em: <http://ccsenet.org/journal/index.php/jsd/ article/view/6331>. Acesso em: 20 ago. 2011.

SANTA CATARINA. Empresa de Pesquisa Agropecuária e Extensão Rural de Santa Catarina S.A. Mapas digitais de Santa Catarina. Florianópolis: EPAGRI/CIRAM, 2010. Estação: 
Concórdia, Campos Novos, Joaçaba, Caçador, Videira e Campos Novos. Disponível em: <http://ciram.epagri.sc.gov. br/mapoteca/>. Acesso em: 22 fev. 2012.

SCHEIBE, L. F. Geologia de Santa Catarina. Geosul, ano 1, n. 1, p. 7-38, 1986.

SCHEIBE, L. F. O sistema aquífero integrado Guarani-Serra Geral em Santa Catarina: uma contribuição para a educação ambiental. In: COLÓQUIO DE EDUCAÇÃO: A FORMAÇÃO DO EDUCADOR NO SÉCULO XXI - EDUCAÇÃO AMBIENTAL E HUMANIZAÇÃO, 2006, São Miguel Do Oeste. Anais... São Miguel do Oeste: Editora UNOESC, 2006.

SCHEIBE, L. F.; HIRATA, R. O contexto tectônico dos sistemas aquíferos Guarani e Serra Geral em Santa Catarina: uma revisão. In: CONGRESSO BRASILEIRO DE ÁGUAS SUBTERRÂNEAS, 15., 2008, Natal. Anais... Natal: Associação Brasileira de Águas Subterrâneas, 2008. v. 1.

SCHEIBE, L. F.; HIRATA, R. O Sistema Aquífero Integrado Guarani/Serra Geral (SAIG/SG) em Santa Catarina e os recursos hídricos da Bacia do Rio do Peixe. In: TREVISOL, J. V.; SCHEIBE, L. F. (Org.). Bacia hidrográfica do Rio do Peixe: natureza e sociedade. Joaçaba: Unoesc, 2011.

SOLOS do Estado de Santa Catarina. Rio de Janeiro: Embrapa Solos, 2004. 1 CD-ROM.; mapa color. - (Embrapa Solos. Boletim de Pesquisa e Desenvolvimento; n. 46). Anexo mapa Levantamento de reconhecimento dos solos do Estado de Santa Catarina. Escala: 1:250.000.

ZANATTA, L. C.; COITINHO, J. B. L. Utilização de Poços Profundos no Aquífero Guarani para Abastecimento Público em Santa Catarina. CONGRESSO BRASILEIRO DE ÁGUAS SUBTERRÂNEAS, 12., 2002, Florianópolis, SC. Anais... 2002. [S.l.: s.n.], 2002. p. 1-16. Disponível em: <aguassubterraneas. abas.org/asubterraneas/article/view/22740>. Acesso em: 01 out. 2009. 